\title{
Climate-driven desertification and its implications for the ancient Silk Road trade
}

\author{
Guanghui Dong ${ }^{1}$, Leibin Wang ${ }^{2}$, David Dian Zhang ${ }^{2}$, Fengwen Liu ${ }^{3}$, Yifu Cui ${ }^{4}$, Guoqiang Li $^{1}$, Zhilin Shi ${ }^{5}$, and \\ Fahu Chen ${ }^{6}$ \\ ${ }^{1}$ Key Laboratory of Western China's Environmental Systems (Ministry of Education), College of Earth and \\ Environmental Sciences, Lanzhou University, Lanzhou 730000, China \\ ${ }^{2}$ Centre for Climate and Environmental Changes, School of Geographical Sciences, \\ Guangzhou University, Guangzhou 510006, China \\ ${ }^{3}$ Institute for Ecological Research and Pollution Control of Plateau Lakes, School of Ecology and Environment Science, \\ Yunnan University, Kunming 650504, China \\ ${ }^{4}$ College of Tourism, Huaqiao University, Quanzhou 362021, China \\ ${ }^{5}$ Institute of Dunhuang Studies, School of History \& Culture, Lanzhou University, Lanzhou 73000, China \\ ${ }^{6}$ Group of Alpine Paleoecology and Human Adaptation (ALPHA), State Key Laboratory of Tibetan Plateau Earth System, \\ Resources and Environment (TPESRE), Institute of Tibetan Plateau Research, Chinese Academy of Sciences, \\ Beijing 100101, China
}

Correspondence: Leibin Wang (wanglb@gzhu.edu.cn)

Received: 29 July 2020 - Discussion started: 7 August 2020

Revised: 15 May 2021 - Accepted: 24 May 2021 - Published: 29 June 2021

\begin{abstract}
The ancient Silk Road played a crucial role in cultural exchange and commercial trade between western and eastern Eurasia during the historical period. However, the exchanges were interrupted in the early 16 th century $\mathrm{CE}$, during the Ming dynasty. Various causes for the decline of the ancient Silk Road have been suggested. Unlike social factors, natural factors have not been adequately addressed. In this study, we use evidence from a sedimentary site (Xishawo, XSW) in Dunhuang oasis, together with analysis of historical archives, to demonstrate the occurrence of extreme droughts and desertification events in the Dunhuang area post $\sim 1450 \mathrm{CE}$, which persisted at least for decades. The desertification may be closely associated with the accessibility of the ancient Silk Road in the area, which was responsible for a steep fall in the volume of trade, as well as political chaos and mass migrations. Therefore, besides socio-economic factors, climate change may have played an important role in trade exchange between the Ming government and the West and may have even influenced the rise and decline of the ancient Silk Road.
\end{abstract}

\section{Introduction}

The ancient Silk Road was the most important link between nations in Eurasia from the 2nd century BCE to the 16th century $\mathrm{CE}$, and thus it indirectly shaped the politics, cultures and economies of populations across the Eurasian continent. The route not only linked commercial trade between the East and West, but it also facilitated the spread of religion, technology and even diseases such as the plague (Jones et al., 2011; Chen et al., 2015; Schmid et al., 2015; Frankopan, 2015; An et al., 2017; Dong et al., 2018; Hao et al., 2020; Afzaal, 2020). The Chinese section of the ancient Silk Road passes through one of the driest regions on Earth, and the logistical operation of the road depended directly on the oases that developed along the foot of the high mountain ranges (the Qilian, Kunlun and Tianshan), mainly as a result of precipitation supplied as streamflow from the highlands. Cities and towns emerged and developed in association with oases, such as Jiayuguan, Dunhuang, Hami and Ruoqiang, which functioned as logistical stations for trade between East and West along the ancient Silk Road. The Jiayuguan Pass was at the western end of the Great Wall during the Ming dynasty. Located at the narrowest point of the Hexi Corridor, 
the Jiayuguan Pass was also a critical location on the primary routeway between the western Gobi Desert and the domains of the Ming dynasty. Dunhuang commandery was $300 \mathrm{~km}$ from the Jiayuguan Pass and was the traffic hub which constituted the historic junction of several routes along the ancient Silk Road in Central Asia (Huang and Wu, 2008). It passed to the control of the central government in $1372 \mathrm{CE}$, during the early Ming dynasty. As a routeway, the ancient Silk Road reached a peak in the Tang dynasty (618-907 CE), but its importance declined substantially in the 16th century CE with the closure of the Jiayuguan Pass by the central government in China and the abandonment of Dunhuang city during the Ming dynasty (1368-1644 CE). This event was an important marker in terms of the severance of cultural exchange and trade between East and West and the decline of the ancient Silk Road as an historically important routeway.

Socioeconomic-related hypotheses have been proposed to explain the decline of the ancient Silk Road during the later Ming Dynasty. For example, frequent wars in the Dunhuang area have been suggested (Chen, 2011; Li and Zheng, 2013). In order to consolidate the frontier territory, from the early Ming dynasty onwards, the Ming governor successively established seven garrisons in the Jiayuguan-Dunhuang area and transferred the leadership to Mongolia, which governed the seven garrisons (Chen, 2000). During the middle and late Ming dynasty, national power declined due to political corruption and financial stresses, but the bordering nations such as Oirat and Turpan continued to expand (Zhang, 1974). Agri-nomadic wars (conflict between agriculturalists and nomads), conflict between the seven garrisons and invasions by nomadic tribes in the Hexi Corridor were frequent. The border policy of the administration weakened and there was a gradual isolation of the governance, especially after "the Tumubao Campaign" in $\sim 1450 \mathrm{CE}$, which is widely regarded as a turning point in the trajectory of the Ming government from prosperity to decline (Research Institute of History and Language of the Central Academy of Taiwan, 1962; Zhang, 1974), and as a consequence the seven-garrisons region, including Dunhuang city, was abandoned. The re-opening of the Maritime Silk Road in the southern part of Ming territory was suggested to be another cause of the interruption of the ancient Silk Road on land (Xie et al., 2007; Qian and Jin, 2010; Zhai, 2017). Additionally, in terms of the international geopolitical situation, after capturing Constantinople in $1453 \mathrm{CE}$, the Ottoman Empire continued to expand across the Balkans, the Middle East and North Africa, with its power and influence reaching a peak in the 16th century. A large and powerful state such as the Ottoman Empire may have blocked trade between Europeans and the Chinese Ming government along the ancient Silk Road (Faroqhi et al., 1994; Beckwith, 2009; Liu, 2014).

On the other hand, a pollen record from the sediments of Lake Tian'e in the Qilian Mountains reveals the occurrence of a distinctly drier climate during 1350-1600 CE, and therefore an environmental-related hypothesis has also been suggested for the timing of the decline of the ancient Silk Road (Zhang et al., 2018). Previous high-resolution tree ring records from the Qilian Mountains revealed the occurrence of drought in the Hexi Corridor during 1450-1550 CE (Gou et al., 2015a, b; Yang et al., 2014), corresponding to the onset of a cold climate during the Little Ice Age (LIA) during CE 1450-1850 (Mann et al., 2009). However, these tree ring and lake sediment records are from the eastern part of the Hexi Corridor, and there are no reliable paleoclimatic records from the Dunhuang area in the western part. Throughout human history, climate change has been regarded as an important and sometimes critical factor for the rise and fall of ancient civilizations (Wang et al., 2018; Tan et al., 2021), such as in the cases of Mesopotamia (Weiss, 1993), the Maya (Kennett et al., 2012; Medina-Elizalde and Rohling, 2012; Nooren et al., 2018), Angkor (Buckley et al., 2010), and the decline of the Loulan Kingdom on the ancient Silk Road (Fontana et al., 2019; Fig. 1).

In the present study, we focus on the role that paleoenvironmental variations may have played on the ancient Silk Road in the Duanhuang-Jiayuguan area, which in terms of the physical environment is the most inhospitable section of the ancient Silk Road, being dominated by the Gobi Desert. First, the results of a detailed sedimentary investigation of the Xishawo site (near Dunhuang city) are presented and the paleoenvironmental change are evaluated. Second, the relevant available literature is reviewed and a sociopolitical analysis of the historical archives in Dunhuang and the surrounding areas in Ming China are used to determine environmental and sociopolitical changes in the area during the study period. Finally, the influence of the natural environment on the trade exchange between the Ming dynasty and Western countries on the abandonment of the Dunhuang area and on the official closure of the ancient Silk Road in the early 16th century CE are reviewed.

\section{Study area}

The Hexi Corridor $\left(37^{\circ} 15^{\prime}\right.$ to $41^{\circ} 30^{\prime} \mathrm{N}, 92^{\circ} 21^{\prime}$ to $\left.104^{\circ} 45^{\prime} \mathrm{E}\right)$ is located to the north of the Qilian Mountains and south of Beishan Mountain. It is long and narrow and stretches for over $1000 \mathrm{~km}$ from Wushaoling Mountain in the east to the boundary of Gansu and Xinjiang provinces in the west, but it extends for only tens to some hundreds of kilometers in the north-south direction (Fig. 1). The area corresponds to the zone of climatic interaction between arid Central Asia and monsoonal Asia and is climatically characterized by a continental monsoon climate influenced by both the westerlies and the monsoon. The annual precipitation is no more than $\sim 200 \mathrm{~mm}$, but the evaporation ranges from 1500 to $3000 \mathrm{~mm}$ (Huang et al., 2017). The annual temperature is $\sim 0-10^{\circ} \mathrm{C}$. The Hexi Corridor consists of three independent landlocked river systems: the Shule River basin, the Heihe River basin and the Shiyang River basin, from west to east. The flow 


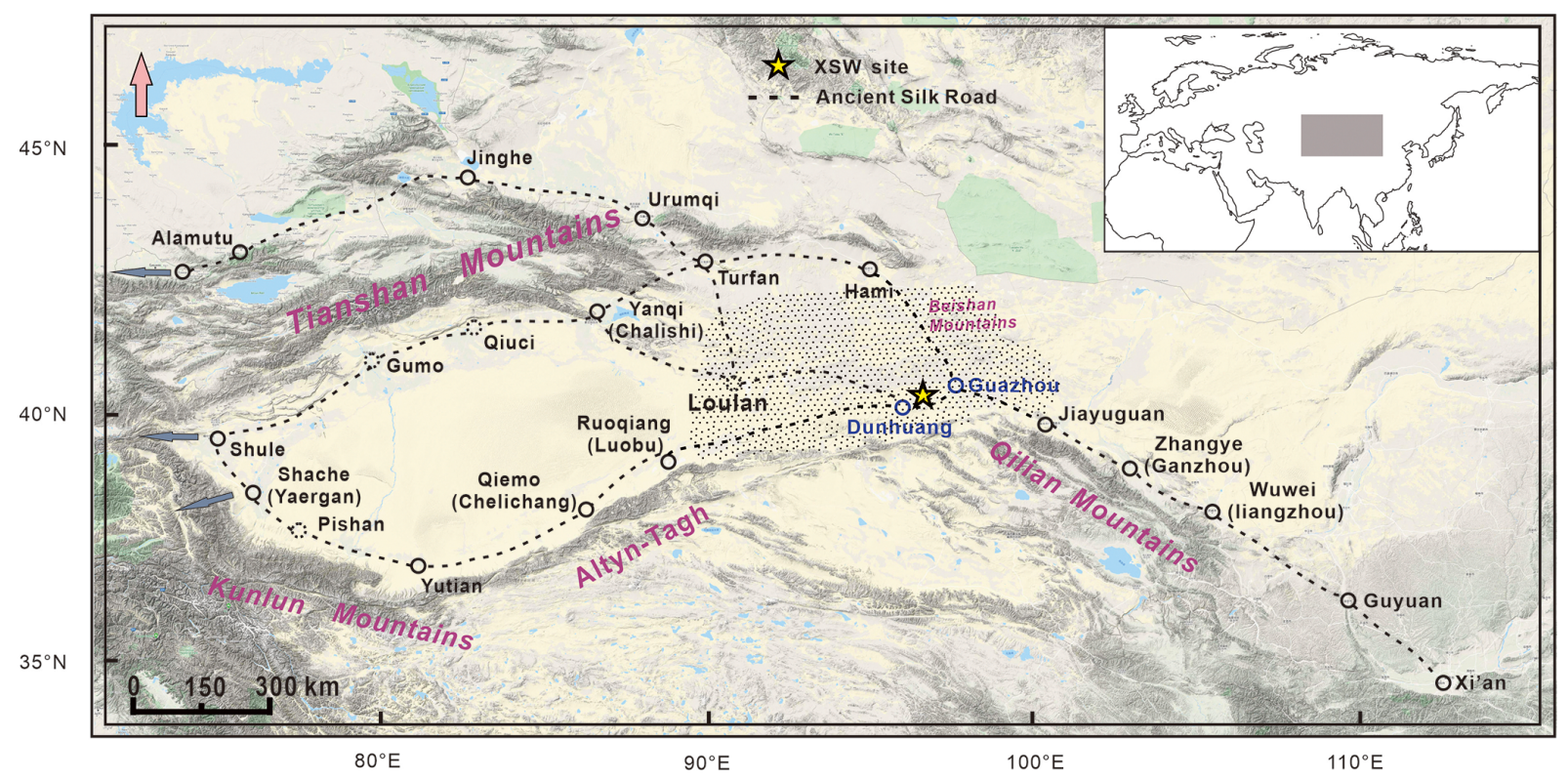

Figure 1. Location of the study area and cities along the ancient Silk Road (dotted circles are oasis cities that were already abandoned before the Ming dynasty, solid circles are oasis cities that still existed during the Ming dynasty, the cities in parentheses were under Ming governorship, and the dotted area is the Gobi Desert near Dunhuang and Guazhou). The base map comes from (C) Google Maps.

of the three rivers is generated by the glaciers of the Qilian Mountains and is consumed in the middle and lower reaches of Owase Lake or in the deserts within the basin. Diverse landscapes of mountains, oases, deserts and Gobi are alternately distributed in the area. The unique topography and location of the Hexi Corridor were largely responsible for its great strategic and military importance to historical dynasties over the past 2000 years. It was also known as the key routeway (the ancient Silk Road) for cultural and commercial exchanges between Chinese and western countries for thousands of years.

The oasis ecological system in arid areas is fragile because of the closed environment, sparse vegetation and water scarcity. However, the bead-like distribution of oases played a crucial role in the exchange of merchandise in Eurasia. Jiayuguan city was the northwestern gateway of the Ming domain and a key fortress along the routeway of EastWest economic exchange. Dunhuang city and Guazhou city ( $\sim 120 \mathrm{~km}$ northeast of Dunhuang) are located in the eastern Gobi Desert to the west of the Jiayuguan pass (Fig. 1). The ancient Silk Road split into three branches in a westerly direction from the region. The northern branch led to the northwest of Hami oasis and the oasis cities of Turfan, Yanqi, Qiuci, and Gumo and then to Central Asia. The central branch passed through Loulan city $(300 \mathrm{~km}$ west of Dunhuang), which was abandoned in $\sim 330$ CE because of eolian activity (Yuan and Zhao, 1999; James, 2007; Fontana et al., 2019). The southern branch connected many cities along the southern edge of the Taklimakan Desert, such as Ruoqiang, Qiemo and Yutian, on the northern piedmont of the Altyn-
Tagh and the Kunlun Mountains (Fig. 1). As can be seen in Fig. 1, the location of Dunhuang oasis led to its importance as the only logistical station between Hami oasis and Ruoqiang oasis and the Jiayuguan oasis during the Ming dynasty.

The Xishawo (XSW) section in this study is located near the ancient city of Xishawo in the modern Gobi Desert area of the Shule River basin. The site is in the middle of the Dunhuang and Guazhou oases, $\sim 50 \mathrm{~km}$ northeast of Dunhuang city (Fig. 1). The Xishawo site was previously an ancient oasis with cultural sites, ancient cities and beacon towers. Relict river channels are present at several locations, although most of them are buried by sand dunes (Li, 1990; Cheng, 2007). The modern annual mean precipitation and annual mean temperature of the area are $45.3 \mathrm{~mm}$ and $8.8^{\circ} \mathrm{C}$, respectively. Previous research has revealed that the Xishawo site was occupied during 900-1400 CE, and the inhabitants cultivated barley, broomcorn and foxtail millet during this period ( $\mathrm{Li}$ et al., 2017). Wind-eroded landforms are common in the region as a consequence of the arid climate, sparse vegetation cover and frequent sandstorms. The exposed part of the XSW section is $\sim 3 \mathrm{~m}$ thick and consists mainly of a sand dune, which is fixed by the dead roots of Salix and therefore preserved. The surface of the profile was cleaned to remove contamination by modern sediments and plant roots. The stratigraphic description of XSW section from the top to $270 \mathrm{~cm}$ depth is as follows: (1) $0-10 \mathrm{~cm}$, fine sand; (2) $10-46 \mathrm{~cm}$, dark-gray paleosol, with a $4 \mathrm{~cm}$ thick black cultural layer at $30-34 \mathrm{~cm}$; (3) $46-100 \mathrm{~cm}$, light-yellowish loess; (4) 100-125 cm, loess-like paleosol; (5) $125-185 \mathrm{~cm}$, dark gray clay with $\mathrm{Fe}-\mathrm{Mn}$ nodules; (6) $185-250 \mathrm{~cm}$, yel- 
low fine sand; and (7) $250-270 \mathrm{~cm}$, black silty clay. A total of 135 samples were collected at a $2 \mathrm{~cm}$ interval for measurements of weight loss-on-ignition (LOI), grain size, and element contents. One wood sample (at the depth of $10 \mathrm{~cm}$, labeled XSW-10) and one charcoal sample (from the cultural layer at $32 \mathrm{~cm}$, labeled XSW-32) were collected for accelerator mass spectrometry radiocarbon (AMS ${ }^{14} \mathrm{C}$ ) dating. Two eolian samples for optically stimulated luminescence (OSL) dating from the fine yellow sand layer $(188$ and $248 \mathrm{~cm}$, labeled XSW-188, XSW-248, respectively) were collected by hammering stainless-steel cylinders into the section vertically, which were immediately sealed with opaque tape after removal.

\section{Methodology}

\subsection{Laboratory analyses}

\subsubsection{Chronology}

AMS ${ }^{14} \mathrm{C}$ and OSL dating were used to establish a chronological framework for the XSW section. The charcoal and wood samples for AMS ${ }^{14} \mathrm{C}$ dating were prepared by the acid-base-acid procedure at the MOE Key Laboratory in Lanzhou University and measured at the AMS ${ }^{14} \mathrm{C}$ dating laboratory of Peking University. The IntCal13 curve, Libby half-life of 5568 years and $\mathrm{OxCal} 4.2$ were used to calibrate all of the dates (Reimer et al., 2013). All ages reported are relative to $1950 \mathrm{CE}$ (referred to as "cal BCE" and "cal CE").

OSL dating was conducted at the OSL Laboratory at the MOE Key Laboratory of Western China's Environmental System, Lanzhou University. Two OSL dating samples were collected from the XSW section. The pretreatment procedure followed that described in Aitken (1998). OSL measurement of coarse-grained (90-125 $\mu \mathrm{m}$ ) quartz were performed using an automated Ris $\varnothing$ TL/OSL DA-20 reader. Laboratory irradiation was carried out using ${ }^{90} \mathrm{Sr} /{ }^{90} \mathrm{Y}$ sources. The quartz OSL signal was detected by a photomultiplier tube through two $3 \mathrm{~mm}$ thick Hoya U-340 filters and the K-feldspar IRSL signal was detected using a package of Corning7-59 and BG39 filters. The purity of the quartz extracts was checked using the IR depletion ratio test (Duller, 2003). A single aliquot regenerative protocol (Murray and Wintle, 2003) was applied to quartz samples to obtain the equivalent dose $\left(D_{\mathrm{e}}\right)$. The concentrations of the radioactive elements uranium $\left({ }^{238} \mathrm{U}\right)$, thorium $\left({ }^{232} \mathrm{Th}\right)$ and potassium $\left({ }^{40} \mathrm{~K}\right)$ were measured by neutron activation analysis (NAA) to calculate the dose rate. The cosmic ray contribution was calculated according to the burial depth and altitude of the samples (Prescott and Hutton, 1994). A water content of $10 \pm 5 \%$ was used to the calculate ages of sand-loess sediments.

\subsubsection{Analysis of climatic proxies}

Measurements of LOI, grain size and element contents were made at the MOE Key Laboratory of Western China's Envi- ronmental System Lanzhou University. LOI measurements were used to determine the organic matter content of the sediments. The measurements were made at a $2 \mathrm{~cm}$ interval and calculated as $\mathrm{LOI}_{550}(\%)=\left(m_{105}-m_{550}\right) / m_{105} \times 100 \%$, where $m_{105}$ is the sample weight after oven-drying at $105^{\circ} \mathrm{C}$, and $m_{550}$ is the sample weight after combustion at $550^{\circ}$ for $4 \mathrm{~h}$ in a muffle furnace.

Samples for grain-size analysis were pre-treated with $10 \%$ $\mathrm{H}_{2} \mathrm{O}_{2}$ and $10 \% \mathrm{HCL}$ to remove organic matter and carbonates, respectively. The samples were then dispersed by ultrasonication with the addition of $10 \%$ sodium hexametaphosphate. Grain-size distributions were measured with a Malvern MS 2000 laser grain-size analyzer.

Samples for the analysis of element contents were pretreated as follows. All samples were oven-dried for $24 \mathrm{~h}$ and then pulverized into a powder. About $4 \mathrm{~g}$ of powder was then pressed into a 4-6 $\mathrm{mm}$ thick and $30 \mathrm{~mm}$ in diameter pellet under $30 \mathrm{t} \mathrm{m}^{-2}$ of pressure. The major, minor and trace element contents were measured with a Magix PW2403 wavelengthdispersive XRF spectrometer. Elemental concentrations of $0.1 \mathrm{ppm}$ to $100 \%$ could be analyzed. $\mathrm{Rb} / \mathrm{Sr}$ ratios were calculated for paleoenvironmental reconstruction.

\subsection{Analysis of published paleoenvironmental records and documentary evidence for the region}

\subsubsection{Previous paleoclimatic records from the region}

All available high-resolution paleoclimatic records for the study area and the adjacent region were reviewed and compared. They include records of regional temperature, precipitation and river flow. In addition, documentary evidence of climate change in the region during the Ming dynasty was investigated.

\subsubsection{Sociohistorical archives}

Sociohistorical records, such as records of the political, economic and military activity of the Ming dynasty, were analyzed (Zhang, 1974; Chinese Military History Writing Group, 2003; Yu, 2003), together with sociohistorical records of the Jiayuguan-Dunhuang area.

\section{Results and discussion}

\subsection{Effects of warfare on the ancient Silk Road}

The Jiayuguan-Dunhuang area experienced frequent political turmoil and conflicts during the Ming dynasty (Zhang, 1974). Warfare in the northwestern part of the Ming domain was suggested to be the main cause for the repeated (twice) closure of the Jiayuguan Pass and the severance of the ancient Silk Road (Gao and Zhang, 1989; Chen, 2011). The Jiayuguan Pass was established in 1372 CE during the early Ming dynasty to resist the remaining elements of the Yuan dynasty (1271-1368 CE), and the Hexi Corridor was under 
the total control of the Ming government during the Ming dynasty. In addition, the Ming dynasty government established seven garrisons to the west of Jiayuguan Pass to reduce pressure on the border (Zhang, 1974). The Jiayuguan Pass was not only a military stronghold but also the primary pass on the ancient Silk road to the West.

In order to investigate the relationship between conflict and the closure of the Jiayuguan Pass, the frequency of agri-nomadic conflict in the Dunhuang area was estimated based on historical archives (Chinese Military History Writing Group, 2003; Yu, 2003). The incidence of agri-nomadic conflicts in the Hexi Corridor was also summarized for comparison (Fig. 2a). The classification of agri-nomadic conflict was adopted because it directly reflects the conflict between the central government and nomadic peoples. The frequency of tribute trade and the number of tribute states in the Western Regions are illustrated in Fig. 2b and c (Chinese Military History Writing Group, 2003; Yu, 2003). All of the data were grouped into 5-year intervals. It is evident that conflicts between agriculturalists and nomads occurred constantly from $1368 \mathrm{CE}$, during the early Ming dynasty, until $1520 \mathrm{CE}$. However, conflicts ceased in the Dunhuang area after $1520 \mathrm{CE}$, which shows that the final closure of the Jiayuguan Pass in 1539 CE substantially reduced the frequency of nomad incursions in the Dunhuang area. However, evidence is still needed to confirm that agri-nomadic conflicts were responsible for the closures of the Jiayuguan Pass in $1524 \mathrm{CE}$ and $1539 \mathrm{CE}$, and for the decline of the ancient Silk Road. For example, it is unclear why - if agri-nomadic conflicts no longer occurred after $1520 \mathrm{CE}$ - the Jiayuguan Pass was closed decades later in $1539 \mathrm{CE}$. It is also unclear why there was a lull in political unrest and violence in the Dunhuang area from $1450 \mathrm{CE}$.

Figure $2 b$ and $c$ show that tribute exchange between the Ming government and the western regions has no obvious relationship with the frequency of conflicts. The tribute trade frequency and the number of tribute states both reached a peak during 1400-1450 CE but then decreased sharply after $1450 \mathrm{CE}$ and subsequently remained at a low level. As Fig. 2a demonstrates, there were frequent agri-nomadic conflicts during 1400-1450 CE, followed by a truce that lasted for about 20 years. However, the tribute trade declined substantially during the truce (1450-1470 CE) and there was no obvious revival until the collapse of the Ming dynasty (Fig. 2b and c).

It has been determined that the Jiayuguan Pass-Dunhuang city route was the crucial routeway connecting the western regions to the core territory of the Ming dynasty (Zhang, 1974). The absence of a relationship between the frequency of wars in the Dunhuang area and variations in the amount of tribute trade demonstrates that an increase in the frequency of warfare was probably not the primary or single cause of the collapse of trade along the ancient Silk Road.

Moreover, war was not solely responsible for the closure of the Jiayuguan Pass. The first closure of the Jiayuguan Pass in $1524 \mathrm{CE}$ may have been a consequence of wars in the Dunhuang area, although wars also occurred frequently during periods when trade flourished (1400-1450 CE) (Fig. 2a). However, subsequently there was a continuous state of peace in the Dunhuang area that lasted for decades, and the city was only abandoned by the final closure of the Jiayuguan Pass in $1539 \mathrm{CE}$. Therefore, we conclude that an increase in the frequency of warfare is not a tenable explanation for the decline of the ancient Silk Road.

\subsection{Influence of climate change on the ancient Silk Road}

\subsubsection{Paleoclimatic record of the XSW section}

The paleoclimatic record of the XSW section in the Dunhuang area was used to assess the possible role of climate change in the decline of the ancient Silk Road. The results of the analysis of various climatically sensitive parameters, together with the ${ }^{14} \mathrm{C}$ and OSL chronology, are illustrated in Table 1 and Fig. 3. The ${ }^{14} \mathrm{C}$ dates for the fine sand layer (XSW-10) and the cultural layer (XSW-32) are 499 \pm 10 cal yr BP (1440$1460 \mathrm{cal} \mathrm{CE})$ and $701 \pm 27 \mathrm{cal}$ yr BP (1224-1278 cal CE), respectively. The two OSL samples from the sand layer are dated to $2.6 \pm 0.2 \mathrm{ka}(800 \pm 300 \mathrm{BCE})$ and $2.8 \pm 0.2 \mathrm{ka}$ $(600 \pm 200 \mathrm{BCE})$ (Table 2). Profiles of grain size, LOI and $\mathrm{Rb} / \mathrm{Sr}$ ratio are shown in Fig. 3a, b, c and d, respectively. The increase in median grain size and of the $>63 \mu \mathrm{m}$ fraction indicate an arid environment and intense wind activity in the Dunhuang area during 800-600 BCE and at $~ 1450 \mathrm{CE}$. The LOI record reflects variation in organic matter content, and the $\mathrm{Rb} / \mathrm{Sr}$ ratio of eolian sediments is positively correlated with weathering intensity. The $\mathrm{Rb} / \mathrm{Sr}$ ratio of the two sand layers is very low (Fig. 3), and therefore the effects of weathering are minor (Gallet et al., 1996; Chen et al., 1999), suggesting that precipitation in the Dunhuang area was low during $\sim 800-600 \mathrm{BCE}$ and after $\sim 1450 \mathrm{CE}$. A comparison of the LOI and $\mathrm{Rb} / \mathrm{Sr}$ profiles indicates that during 800-600 BCE and after $~ 1450 \mathrm{CE}$ the organic matter content of the section was low and chemical weathering was weak. These results suggest the occurrence of overall arid conditions, frequent dust storms and associated desertification events during 800-600 BCE, i.e., the Spring and Autumn period (771-476 BCE) of the Eastern Zhou Dynasty, and after $\sim 1450 \mathrm{CE}$ (the Ming dynasty). These conditions would have been very unfavorable for human habitation of the area.

The two desertification events recorded in the XSW section were not solely local events. A cold and dry climate at these times is also evident in paleoclimatic records from the nearby Qilian Mountains and the Tibetan Plateau. A tree ring record from the Qilian Mountains suggests that precipitation was low during 900-550 BCE (Yang et al., 2014). A pollen record from Juyanze lake indicates the low representation of tree pollen at the same time (Herzschuh et al., 2004). The 


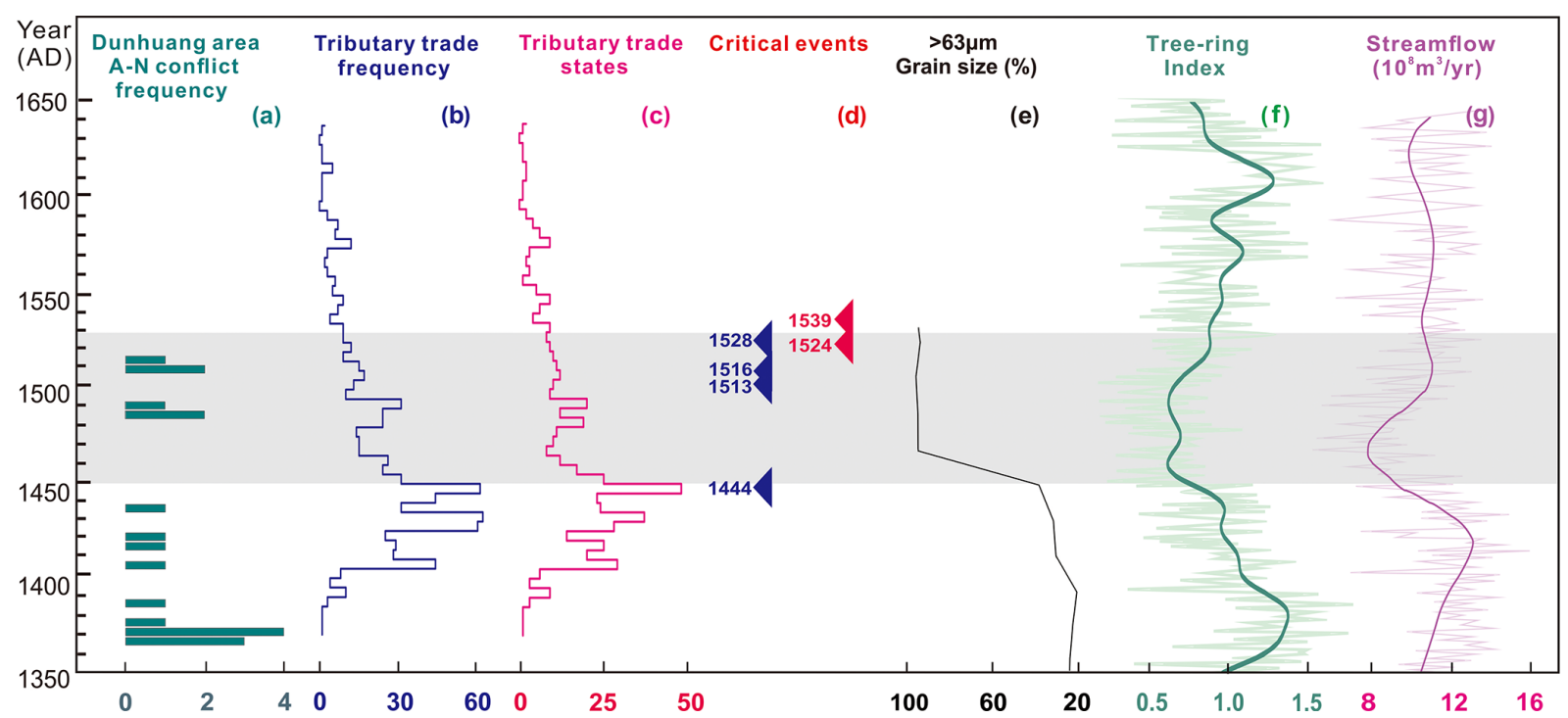

Figure 2. Comparison of records of wars, climate change and cultural events in the Dunhuang area during the Ming-Qing dynasties. (a) Frequency of agri-nomadic wars in the Dunhuang area. (b) Tribute trade through the Jiayuguan Pass between the Ming government and Western countries. (c) Number of tribute states located to the west of Ming China. (d) Major events during the Ming dynasty (blue triangles are mass migrations, red triangles indicate the closure of the Jiayuguan Pass, and the green triangle indicates the abandonment of Dunhuang city). (e) Grain size ( $>63 \mu \mathrm{m}$ fraction) of the XSW section (this study). (f) Tree-ring-based precipitation record from the western Qilian Mountains (after smoothing) (Gou et al., 2015a). (g) Tree-ring-based streamflow record from the upper reaches of the Heihe River (after smoothing) (Yang et al., 2012).

Table 1. Radiocarbon dating results for the Xishawo (XSW) section.

\begin{tabular}{|c|c|c|c|c|}
\hline \multirow[t]{2}{*}{ Lab no. } & \multirow[t]{2}{*}{ Materials } & \multirow{2}{*}{$\begin{array}{r}\text { Conventional }{ }^{14} \mathrm{C} \\
\text { age (years BP) }\end{array}$} & \multicolumn{2}{|c|}{ Calibrated ages (years BP) CE } \\
\hline & & & \multicolumn{2}{|c|}{$2 \sigma(95.4 \%)$} \\
\hline LZU127 & Tree bark & $425 \pm 15$ & $499 \pm 10(478-514)$ & $1440-1460 \mathrm{CE}$ \\
\hline LZU1417 & charcoal & $765 \pm 40$ & $701 \pm 27(659-760)$ & $1190-1291 \mathrm{CE}$ \\
\hline
\end{tabular}

$\delta^{18} \mathrm{O}$ record from the Agassiz ice cap in the high Arctic indicates relatively low temperatures during $\sim 800-600 \mathrm{BCE}$ (Lecavalier et al., 2017), which is correlative with records from the Guliya ice core in the Tibetan Plateau (Thompson et al., 1997). The timing of the second desertification event in the Dunhuang area, in $\sim 1450 \mathrm{CE}$, coincides well with changes in a tree ring record from mountains in the western Hexi Corridor, which suggests an interval of persistent low precipitation during 1430-1540 CE (Fig. 2f, Gou et al., 2015a). An interval of reduced precipitation during this time is also widely recorded in other high-resolution tree ring records from the northern Tibetan Plateau (Gou et al., 2015b; Yang et al., 2014), and in the laminated sediments of Sugan lake in the western Qaidam Basin (Qiang et al., 2005). A decrease in global temperature at $\sim 1450 \mathrm{CE}$ has also been widely detected in high-resolution paleoclimatic records from various locations (Thompson et al., 1997; Wilson et al., 2016; Lecavalier et al., 2017) and is also recorded in historical documentary records from China (Ge et al., 2003). This evidence indicates the occurrence of two deser- tification events in the Dunhuang area and elsewhere, during $\sim 800-600 \mathrm{BCE}$ and after $\sim 1450 \mathrm{CE}$, that were related to regional-scale climatic and environmental deterioration.

As mentioned earlier, the oasis ecological system in arid regions is relatively fragile, with the major limiting factor being water availability (Qian and Jin, 2010). At the present time, vegetation survival in the oasis of the Hexi Corridor depends mainly on runoff from the Qilian Mountains, which is derived firstly from precipitation in the highlands and secondly from glacier meltwater (Liu et al., 2010; Yang et al., 2011; Sakai et al., 2012). The prominent long interval of reduced precipitation and temperature in the Qilian Mountains and in the Tibetan Plateau during $\sim 800$ $600 \mathrm{BCE}$ and at $\sim 1450 \mathrm{CE}$ caused a large decrease in runoff to the lowlands of the Hexi Corridor, which in turn caused vegetation degradation and the extension of the Gobi Desert. Compared to other oasis cities along the ancient Silk Road, which were much closer to the high mountain glaciers (above $4500 \mathrm{~m}$ a.s.l., Fig. 1) that provided a constant supply of meltwater, Dunhuang oasis was located much closer to the center 

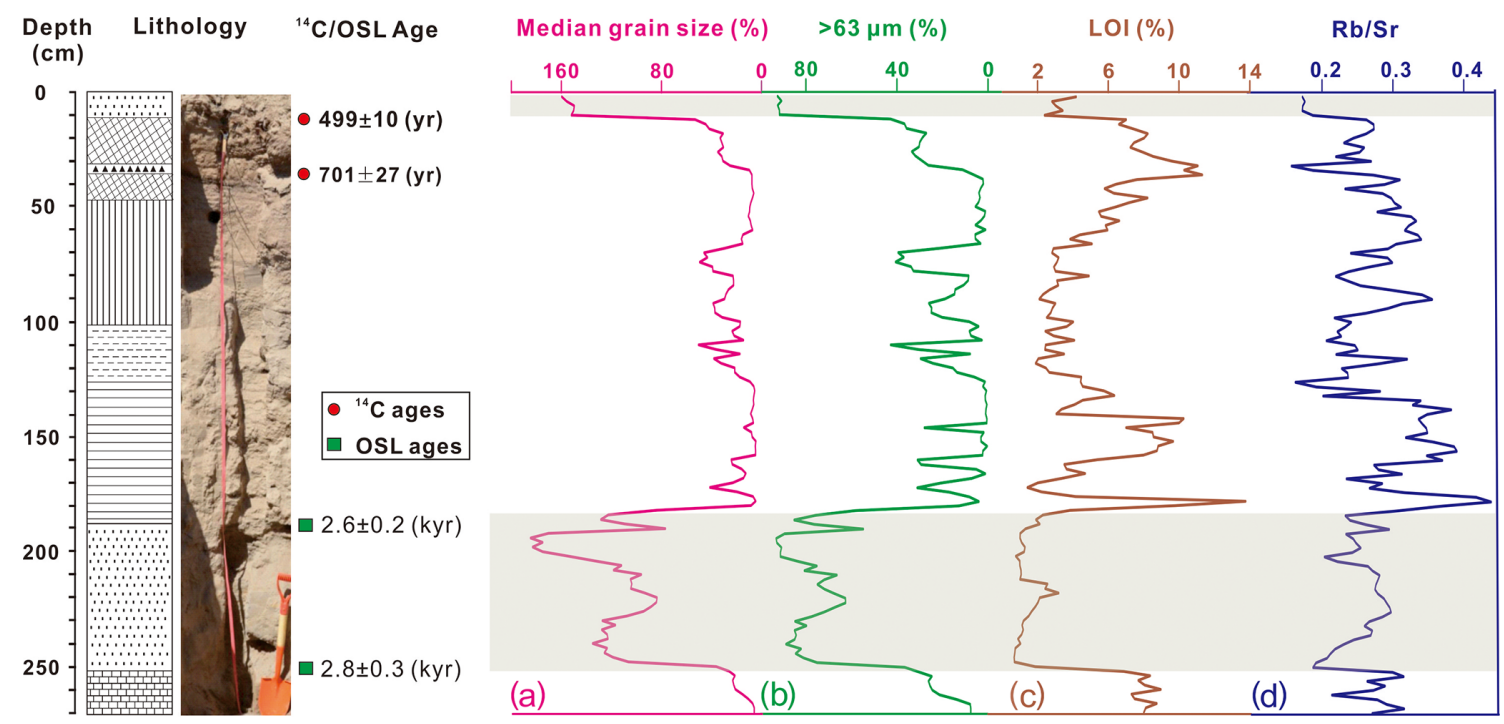

.:. Sand Paleosol $₫$ Culturallayer

圌 Clay 盂 Loess 国 Loess-like soil目 Shallow lacustrine sediment

Figure 3. Lithology, ${ }^{14} \mathrm{C}$ and OSL ages, and climatic proxies for the XSW section: (a) median grain size (Md), (b) $>63 \mu \mathrm{m}$ fraction, (c) loss on ignition (LOI), and (d) $\mathrm{Rb} / \mathrm{Sr}$ ratio.

Table 2. OSL dating results for the Xishawo (XSW) section.

\begin{tabular}{lrrrrrrrrrr}
\hline Lab no. & $\begin{array}{r}\text { Depth } \\
(\mathrm{cm})\end{array}$ & $\begin{array}{r}\text { Grain } \\
\text { size } \\
(\mu \mathrm{m})\end{array}$ & $\begin{array}{r}D_{\mathrm{e}} \\
(\mathrm{Gy})\end{array}$ & $\begin{array}{r}\mathrm{OD} \\
(\%)\end{array}$ & $\begin{array}{r}\mathrm{U} \\
(\mathrm{ppm})\end{array}$ & $\begin{array}{r}\mathrm{Th} \\
(\mathrm{ppm})\end{array}$ & $\begin{array}{r}\mathrm{K} \\
(\%)\end{array}$ & $\begin{array}{r}\text { Cosmic } \\
\text { dose rate } \\
\left(\mathrm{Gy} \mathrm{ka}^{-1}\right)\end{array}$ & $\begin{array}{r}\text { Dose rate } \\
\left(\mathrm{Gy} \mathrm{ka}^{-1}\right)\end{array}$ & $\begin{array}{r}\text { Age } \\
(\mathrm{ka})\end{array}$ \\
\hline XSW-170 & 170 & $90-125$ & $4.4 \pm 0.2$ & 3.9 & $1.43 \pm 0.06$ & $4.72 \pm 0.17$ & $0.98 \pm 0.04$ & 0.20 & $1.7 \pm 0.1$ & $2.6 \pm 0.2$ \\
XSW-235 & 235 & $90-125$ & $5.1 \pm 0.4$ & 16.9 & $1.46 \pm 0.06$ & $5.03 \pm 0.18$ & $1.10 \pm 0.04$ & 0.18 & $1.8 \pm 0.1$ & $2.8 \pm 0.3$ \\
\hline
\end{tabular}

of the Gobi, and therefore it experienced severe desertification which may have resulted in its abandonment.

\subsubsection{Archeological evidence of climate change in the Dunhuang area}

The relatively dense distribution of prehistoric sites in the Hexi Corridor reflects the past intensity of human settlement in the area as well as the habitability of the surrounding environment (Bureau of National Cultural Relics, 2011; Yang et al., 2019). The Hexi Corridor was extensively settled from the Majiayao period (3300-2000 BCE) (Li, 2011), and foxtail millet and broomcorn millet, which were domesticated in northern China, were cultivated in the region (Zhou et al., 2016; Dong et al., 2018). Innovations in agricultural technology facilitated the rapid development of bronze cultures in the Hexi Corridor and the surrounding areas in the succeeding millennium (Dong et al., 2016; Zhou et al., 2016). However, there is a gap in radiocarbon dates during $\sim 850$ $650 \mathrm{BCE}$ in the western Hexi Corridor and eastern Xinjiang (Fig. A1), which suggests a hiatus in cultural evolution and exchange during this period. This hiatus corresponds well to the desertification event in the Dunhuang area of the west- ern Hexi Corridor during 800-600 BCE (Fig. 3). However, even though the climate fluctuated substantially in northwest China during the Bronze Age, human settlement was continuous in the eastern Hexi Corridor at the same longitude (Fig. A1), which suggests that human occupation of the Hexi Corridor was primarily determined by the environmental conditions.

The second desertification event occurred at $\sim 1450 \mathrm{CE}$ and is recorded both in the sand layer of the XSW profile and in the historical and cultural literature. The drought in the Dunhuang area at this time was described as follows: "The wind shakes the Tamarix in thousands of miles of uninhabited land" and "the moon shines on the quicksand on each departed day" (Huang and $\mathrm{Wu}, 2008$ ). The ancestors of the Uyghur people, who originally settled in the Duanhuang area after the abandonment of Dunhuang, sang folk songs about the human migrations through the Jiayuguan Pass during the Ming dynasty (Chen, 2011). An epic of the migration of the Uyghur history contains the following passage: "Violent winds swept livestock away, sand dunes submerged tents and houses, rivers dried up, grassland was devastated" (Wang, 1992; Editorial Group of a Brief History of 
the Uyghur minority, 2008). From these descriptions it can be deduced that the prolonged drought at $\sim 1450 \mathrm{CE}$ may have led to the disappearance of the oasis. The altered ecoenvironment would have reduced the productivity of agriculture and animal husbandry, which would have caused a local food shortage. The deteriorated environment was very likely another cause of mass migration in addition to warfare. The changing geopolitical situation in the western Hexi Corridor and eastern Xinjiang was an important factor in the abandonment of the Dunhuang area by the Ming government, and the extreme and the persistent drought event after $\sim 1450 \mathrm{CE}$ may have intensified the social upheaval and chaos (Fig. 2d, blue triangles highlight mass migrations) that triggered this significant historical event. Notably, a significant relationship has been observed between decreased precipitation, wars and the abandonment of cultivated land in the region during the last 2000 years ( $\mathrm{Li}$ et al., 2019).

\subsubsection{Desertification events in the ancient Silk Road area}

Various indicators of climatic variations, wars and the tribute trade are plotted in Fig. 2 versus the chronological sequence of the Ming dynasty (1368-1644 CE). Under the premise that at $\sim 1450 \mathrm{CE}$ the environment was characterized by a cold and dry climate with intense sandstorms (Fig. 2e), low precipitation (Fig. 2f) and decreased streamflow (Fig. 2g), there is a possibility that climate change played a role on the tribute trade of the ancient Silk Road. There was an abrupt decrease in the frequency of tribute trade at $\sim 1450 \mathrm{CE}$ but not during the two closures of the Jiayuguan Pass in $1524 \mathrm{CE}$ and $1539 \mathrm{CE}$ (Fig. $2 \mathrm{~b}$ and d). In addition, at this time there was a lull in conflicts in the Dunhuang area (Fig. 2a). Therefore, it is proposed that environmental deterioration likely contributed to the decline of the tribute trade and the cessation of hostilities. Climatic perturbations and environmental degradation may not necessarily be a direct trigger of a societal crisis, but they may instead result in institutional failure caused by the lack of a centralized response to an environmental crisis (Feng et al., 2019; White and Pei, 2020). Social disturbance associated with migrations and chaos in the Ming dynasty was likely an indirect consequence of environmental changes. For example, the consequences of a deteriorating environment would include the shrinkage of the habitat and agricultural land necessary for human survival, multiple waves of human migrations into the eastern part of the Hexi Corridor, and the shift of the frontier from Dunhuang to the Jiayuguan pass. Thus, the population decline in the Dunhuang area during the early Ming Dynasty was most probably a "domino effect" (Feng et al., 2019).

The influence of the desertification event in $\sim 1450 \mathrm{CE}$ on the streamflow of the Qilian Mountains gradually decreased after the 1520s CE (Fig. 2f and g). However, the formation and evolution of an oasis is a long-term process (Stamp, 1961; Zhang and $\mathrm{Hu}, 2002$; Li et al., 2016), and the eco- logical response of an oasis to climatic drying would not to be to disappear immediately (Fan, 1993). Moreover, it takes at least 15-20 years for the recovery of a degraded oasis following destruction by $\sim 1-3$ years of human activity (Zhang and $\mathrm{Hu}, 2002$ ). Therefore, the regeneration of a degraded oasis would take much longer than a change in the streamflow. Overall, we propose that the abrupt decrease in tribute exchange and prosperity, or even the decline of the ancient Silk Road overall, may have been affected by the deterioration of the environment along the routeway in the Ming dynasty (Fig. 2b and c).

We now address the issue of how the desertification at $\sim 1450 \mathrm{CE}$ in the Dunhuang oasis and adjacent regions may have affected the functioning of the ancient Silk Road. First, trading in the arid environment of the ancient Silk Road led to the increase in the importance of oasis cities. Camel caravans needed supplies of grain and water from an oasis as they traversed the extensive desert along the road. The desertification events recorded in the XSW section and in the adjacent regions indicate that Dunhuang oasis and Guazhou oasis were not functioning at $\sim 1450 \mathrm{CE}$. This lengthened the distance from the Jiayuguan oasis in the Hexi Corridor to the western oasis in Xinjiang (Fig. 1). According to several researchers, camel caravans in desert areas were able to travel a maximum distance of $\sim 30 \mathrm{~km} \mathrm{~d}^{-1}$ (Shui, 1990; Wang et al., 2000). In addition, the metabolism of a domesticated camel will decrease within $20 \mathrm{~d}$ from the beginning of water deprivation (Chen, 1982). Under working conditions, camels can go for $\sim 10-15 \mathrm{~d}$ without water under a mean ambient temperature of $35^{\circ} \mathrm{C}$ (Kataria et al., 2001). A camel caravan took $59 \mathrm{~d}$ to traverse the $1400 \mathrm{~km}$ of the Taklimakan Desert in 1993 CE under modern climatic conditions, which are much more favorable than in $\sim 1450 \mathrm{CE}$, and the maximum distance was $24 \mathrm{~km}$ in $1 \mathrm{~d}$ (Blackmore, 2000). The maximum distance for a caravan in the water-limited environment on the Silk Road was $30 \mathrm{~km} \mathrm{~d}^{-1} \times 15 \mathrm{~d}=450 \mathrm{~km}$. The distances of Hami, Ruojiang and Jiayuguan to Dunhuang, located in the Gobi Desert in an area without high mountains, are already close to or above this limit, which is barely sufficient for camel travel (shown by the dots in Fig. 1, near the Dunhuang and Shazhou oases). On the other hand, the distances between the oases along the routes on the piedmonts of the high mountain ranges (Qilian, Kunlun and Tianshan) are generally less than $200 \mathrm{~km}$ as the high mountain ranges provide meltwater. After the desertification event, the distances between Jiayuguan and Hami oases (the northern route of the ancient Silk Road) and between Jiayuguan and Ruoqiang oases (the southern route) increased to $\sim 600$ and $\sim 1000 \mathrm{~km}$, respectively. This is close to the maximum distance that a camel caravan can achieve $(\sim 450 \mathrm{~km})$ without a water supply, and would have substantially increased the difficulty of travel across the region and was likely to be the physical cause of the decline of the ancient Silk road during the periods of desertification. 


\section{Conclusion}

We have systematically investigated a possible climatic cause of the interruption of the operation of the ancient Silk Road during the Ming Dynasty. A compilation of the results of absolute dating and high-resolution paleoclimatic records from the XSW site in the Dunhuang area and historical archives reveals that two desertification events occurred, at $\sim 800$ $600 \mathrm{BCE}$ and $\sim 1450 \mathrm{CE}$. The later desertification event was consistent with the immediate fall in tribute trade that occurred in $\sim 1450 \mathrm{CE}$, which indicates that environmental deterioration may have disrupted the trading exchanges by draining the oases in Dunhuang and Guazhou city, which were strategic logistical stations in the vast Gobi Desert. This resulted in traveling distances between supply stations exceeding the physical limit for camel caravans and an irreversible decline in trade exchange. On the other hand, the incidence of agri-nomadic conflicts from historical archives suggests that warfare alone is not the best explanation for the severance of exchanges between Western countries and the Ming government. Hence, we propose that climate change also played a potentially important role in explaining the decline of the ancient Silk Road trade. 


\section{Appendix A}

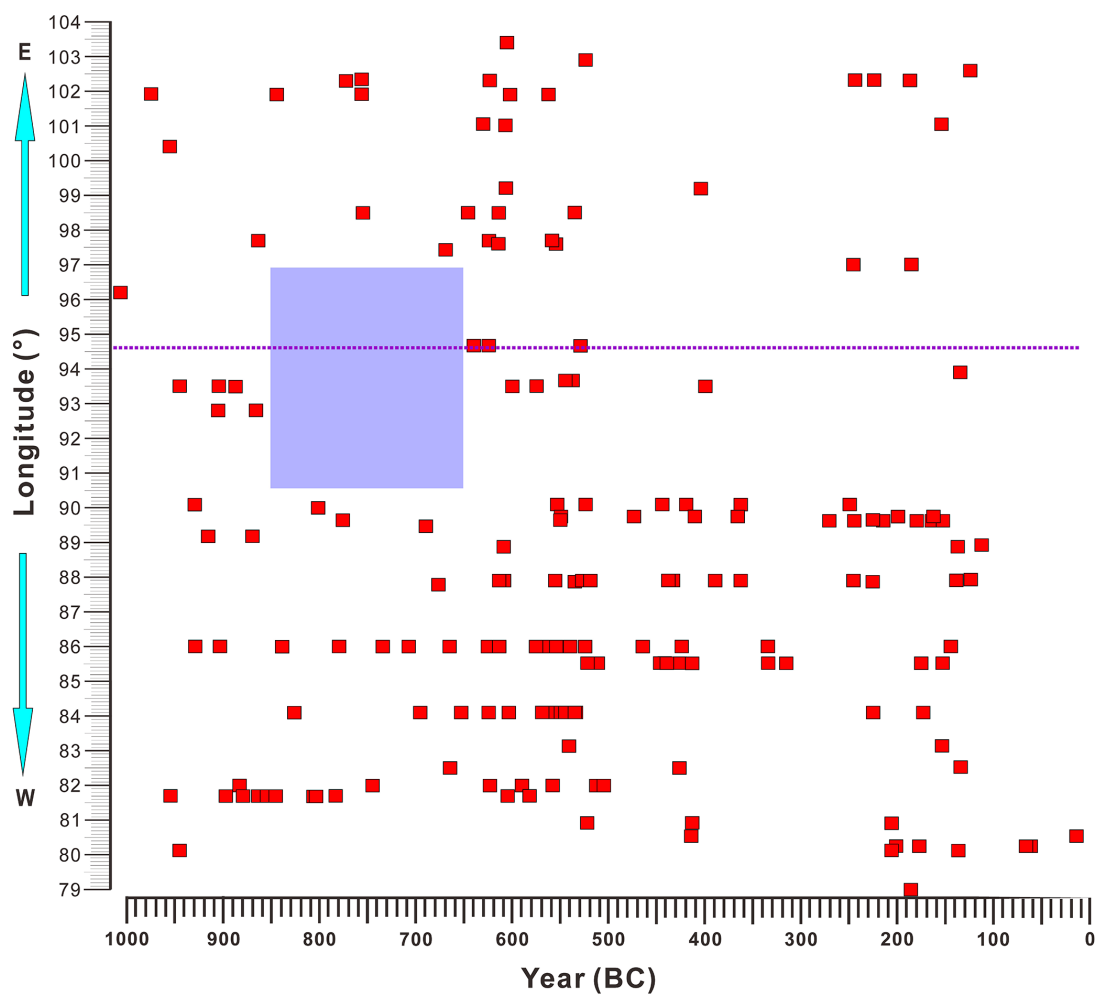

Figure A1. Comparison of the longitude and median dates of Bronze Age cultural sites in the western Hexi Corridor and eastern Xinjiang. The purple rectangle corresponds to an absence of dates in the western Hexi Corridor and Xinjiang. The purple line shows the longitude of the XSW section. 
Data availability. For access to the data in this research, the first author and corresponding author both could be contacted (Guanghui Dong: ghdong@1zu.edu.cn; Leibin Wang: wanglb@gzhu.edu.cn).

Author contributions. GD, LW and DDZ designed the study. FL, YC and GL performed the climatic proxies and dating experiments. ZS analyzed the sociohistorical records. GD, LW and FL designed the figures. GD and LW drafted the manuscript. DDZ and FC supervised the project. All authors discussed the results and commented on the manuscript.

Competing interests. The authors declare that they have no conflict of interest.

Disclaimer. Publisher's note: Copernicus Publications remains neutral with regard to jurisdictional claims in published maps and institutional affiliations.

Special issue statement. This article is part of the special issue "International methods and comparisons in climate reconstruction and impacts from archives of societies". It is not associated with a conference.

Acknowledgements. We thank Teng Li and Shengda Zhang for their suggestions and discussions which inspired this study. We also thank Jan Bloemendal for improving the English.

Financial support. This research has been supported by the National Key R\&D Program of China (grant no. 2018YFA0606402) and the National Natural Science Foundation of China (grant nos. 41825001, 41971110, and 41901098).

Review statement. This paper was edited by Sam White and reviewed by four anonymous referees.

\section{References}

Afzaal, M.: Silk Road to Belt Road: reinventing the past and shaping the future, Asia Pac. Bus. Rev., 26, 104-107, 2020.

Aitken, M. J.: Introduction to optical dating: the dating of Quaternary sediments by the use of photon-stimulated luminescence, Clarendon Press, Oxford, UK, 1998.

An, C. B., Wang, W., Duan, F. T., Huang, W., and Chen, F. H.: Environmental changes and cultural exchange between East and West along the Silk Road in arid Central Asia, Acta Geogr. Sin., 72, 875-891, 2017 (in Chinese).

Beckwith, C. I.: Empires of the silk road: A history of central Eurasia from the Bronze Age to the present, Princeton University Press, New Jersey, USA, 2009.
Blackmore, C.: Crossing the Desert of Death: Through the Fearsome Taklamakan, John Murray press, London, UK, 2000.

Buckley, B. M., Anchukaitis, K. J., Penny, D., Fletcher, R., Cook, E. R., Sano, M., Nam, L. C., Wichienkeeo, A., Minh, T. T., and Hong, T. M.: Climate as a contributing factor in the demise of Angkor, Cambodia, P. Natl. Acad. Sci. USA, 107, 6748-6752, 2010.

Bureau of National Cultural Relics: Atlas of Chinese Cultural Relics-Fascicule of Gansu Province, Surveying and Mapping Press, Beijing, China, 2011 (in Chinese).

Chen, C.: Annals of the western vassal states, China Publishing House, Beijing, China, 2000 (in Chinese).

Chen, F. H., Dong, G. H., Zhang, D. J., Liu, X. Y., Jia, X., An, C. B., Ma, M. M., Xie, Y. W., Barton, L., Ren, X. Y., Zhao, Z. J., Wu, X. H., and Jones, M. K.: Agriculture facilitated permanent human occupation of the Tibetan Plateau after 3600 BP, Science, 347, 248-250, 2015.

Chen, G. W.: Research on the abandonment of the Dunhuang during Ming Dynasty, J. Dunhuang Stud., 60, 111-118, 2011 (in Chinese).

Chen, J., An. Z. S., and Head, J.: Variation of $\mathrm{Rb} / \mathrm{Sr}$ ratios in the loess-paleosol sequences of central China during the last 130,000 years and their implications for monsoon paleoclimatology, Quat. Res., 51, 215-219, 1999.

Chen, Z.: Determination of hunger and thirst tolerance of camel, Animal husbandry and veterinary, 2, 56-58, 1982 (in Chinese).

Cheng, H. Y.: The Desertification of the Hexi Area in Historical Time, Doctoral Dissertation, Lanzhou University, Lanzhou, China, 2007 (in Chinese with English abstract).

Chinese Military History Writing Group: Chronology of China's Ancient War, People's Liberation Army press, Beijing, China, 2003 (in Chinese).

Dong, G. H., Ren, L. L., Jia, X., Liu, X. Y., Dong, S. M., Li, H. M., Wang, Z. X., Xiao, Y. M., and Chen, F. H.: Chronology and subsistence strategy of Nuomuhong Culture in the Tibetan Plateau, Quatern. Int., 426, 42-49, 2016.

Dong, G. H., Yang, Y. S., Liu, X. Y., Li, H. M., Cui, Y. F., Wang, H., Chen, G. K., Dodson, J., and Chen, F. H.: Prehistoric transcontinental cultural exchange in the Hexi Corridor, northwest China, Holocene, 28, 621-628, 2018.

Duller, G. A. T.: Distinguishing quartz and feldspar in single grain luminescence measurements, Radiat. Meas., 37, 161-165, 2003.

Editorial Group of a Brief History of the Yugur minority: Brief history for Yugur minority, The Ethnic Publishing House, Beijing, China, 2008 (in Chinese).

Fan, Z. L.: A study on the formation and evolution of Oases in Tarim Basin, Acta Geographica Sinica, 48, 421-427, 1993.

Faroqhi, S., McGowan, B., and Pamuk, S.: An economic and social history of the Ottoman Empire, 1300-1914, Cambridge University Press, Cambridge, USA, 1994.

Feng, Q., Yang, L., Deo, R. C., AghaKouchak, A., Adamowski, J. F., Stone, R., Yin, Z. L., Liu, W., Si, J. H., Wen, X. H., Zhu, M., and Cao, S. X.: Domino effect of climate change over two millennia in ancient China's Hexi Corridor, Nat. Sustain., 2, $957-$ 961, 2019.

Fontana, L., Sun, M. J., Huang, X. Z., and Xiang, L. X.: The impact of climate change and human activity on the ecological status of Bosten Lake, NW China, revealed by a diatom record for the last 2000 years, Holocene, 29, 1871-1884, 2019. 
Frankopan, P.: The silk roads: A new history of the world, Bloomsbury Publishing, London, UK, 2015.

Gallet, S., Jahn, B. M., and Torii, M.: Geochemical characterization of the Luochuan loess-paleosol sequence, China, and paleoclimatic implications, Chem. Geol., 133, 67-88, 1996.

Gao, F. S. and Zhang, J. W.: Jiayuguan Pass and the Great Wall of Ming dynasty, Heritage Press, Beijing, China, 1989 (in Chinese).

Ge, Q. S., Zheng, J. Y., Fang, X. Q., Man, Z. M., Zhang, X. Q., Zhang, P. Y., and Wang, W. C.: Winter half-year temperature reconstruction for the middle and lower reaches of the Yellow River and Yangtze River, China, during the past 2000 years, Holocene, 13, 933-940, 2003.

Gou, X. H., Gao, L. L., Deng, Y., Chen, F. H., Yang, M. X., and Still, C.: An 850-year tree-ring-based reconstruction of drought history in the western Qilian Mountains of northwestern China, Int. J. Climatol., 35, 3308-3319, 2015a.

Gou, X. H., Deng, Y., Gao, L. L., Chen, F. H., Cook, E., Yang, M. X., and Zhang, F.: Millennium tree-ring reconstruction of drought variability in the eastern Qilian Mountains, northwest China, Clim. Dyn., 45, 1761-1770, 2015 b.

Hao, Z. X., Zheng, J. Y., Yu, Y. Z., Xiong, D. Y., Liu, Y., and Ge, Q. S.: Climatic changes during the past two millennia along the Ancient Silk Road, Prog. Phys. Geog., 44, 605-623, 2020.

Herzschuh, U., Tarasov, P., Wünnemann, B., and Hartmann, K.: Holocene vegetation and climate of the Alashan Plateau, NW China, reconstructed from pollen data, Palaeogeogr. Palaeoclimatol. Palaeoecol., 211, 1-17, 2004.

Huang, S., Feng, Q., Lu, Z. X., Wen, X. H., and Deo, R. C.: Trend Analysis of Water Poverty Index for Assessment of Water Stress and Water Management Polices: A Case Study in the Hexi Corridor, China, Sustainability, 9, 756, https://doi.org/10.3390/su9050756, 2017.

Huang, W. W. and Wu, S. G.: New Local Records of Suzhou. China Publishing House, Beijing, China, 2008.

James, A. M.: Eurasian Crossroads: A history of Xinjiang, Columbia University Press, New York, USA, 2007.

Jones, M. K., Hunt, H., Lightfoot, E., Lister, D., Liu, X. Y., and Matuzeviciute, G. M.: Food globalization in prehistory, World Archaeol., 43, 665-675, 2011.

Kataria, N., Kataria, A. K., Agarwal, V. K., Garg, S. L., and Sahani, M. S.: Filtered and excreted loads of urea in different climatic conditions and hydration states in dromedary camel, J. Camel. Pract. Res., 8, 203-207, 2001.

Kennett, D. J., Breitenbach, S. F., Aquino, V. V., Asmerom, Y., Awe, J., Baldini, J. U. L., Bartlein, P., Culleton, B. J., Ebert, C., Jazwa, C., Macri, M. J., Marwan, N., Polyak, V., Prufer, K. M., Ridley, H. E., Sodemann, H., Winterhalder, B., and Haug, G. H.: Development and disintegration of Maya political systems in response to climate change, Science, 338, 788-791, 2012.

Lecavalier, B. S., Fisher, D. A., Milne, G. A., Vinther, B. M., Tarasov, L., Huybrechts, P., Lacelle, D., Main, B., Zheng, J., Bourgeois, J., and Dyke, A. S.: High Arctic Holocene temperature record from the Agassiz ice cap and Greenland ice sheet evolution, P. Natl. Acad. Sci. USA, 114, 5952-5957, 2017.

Li, B. C.: Investigation on the Ancient Ruins in the Western Sandy land of Minqin County, J. Desert Res., 10, 35-42, 1990 (in Chinese with the English abstract).

Li, H. M., Liu, F. W., Cui, Y. F., Ren, L. L., Storozum, M. J., Qin, Z., Wang, J., and Dong, G. H.: Human settlement and its in- fluencing factors during the historical period in an oasis-desert transition zone of Dunhuang, Hexi Corridor, northwest China, Quatern. Int., 458, 113-122, 2017.

Li, J. and Zheng, B. L.: Historical geography of Dunhuang, Gansu Education Press, Lanzhou, China, 2013 (in Chinese).

Li, S. C.: The Report of Prehistoric Archaeology Survey in The Hexi Corridor, Cultural Relics Press, Beijing, China, 2011 (in Chinese).

Li, X., Yang, K., and Zhou, Y.: Progress in the study of oasis-desert interactions, Agr. Forest Meteorol., 230-231, 1-7, 2016.

Li, Y. P., Ge, Q. S., Wang, H. J., Liu, H. L., and Tao, Z. X.: The relationships between climate change, agricultural development and social stabilities in Hexi Corridor over the last 2000 years, Sci. China Earth Sci., 62, 1453-1460, 2019.

Liu, Y., Sun, J., Song, H., Cai, Q., Bao, G., and Li, X.: Tree-ring hydrologic reconstructions for the Heihe River watershed, western China since AD 1430, Water Res., 44, 2781-2792, 2010.

Liu, Y. S.: The Silk Road, Jiangsu People's Publishing House, Nanjing, China, 2014.

Mann, M. E., Zhang, Z. H., Rutherford, S., Bradley, R. S., Hughes, M. K., Shindell, D., Ammann, C., Faluvegi, G., and Ni, F. B.: Global signatures and dynamical origins of the Little Ice Age and Medieval Climate Anomaly, Science, 326, 1256-1260, 2009.

Medina-Elizalde, M. and Rohling, E. J.: Collapse of Classic Maya civilization related to modest reduction in precipitation, Science, 335, 956-959, 2012.

Murray, A. S. and Wintle, A. G.: The single aliquot regenerative dose protocol: potential for improvements in reliability, Radiat. Meas., 37, 377-381, 2003.

Nooren, K., Hoek, W. Z., Dermody, B. J., Galop, D., Metcalfe, S., Islebe, G., and Middelkoop, H.: Climate impact on the development of Pre-Classic Maya civilisation, Clim. Past, 14, 12531273, https://doi.org/10.5194/cp-14-1253-2018, 2018.

Prescott, J. R. and Hutton, J. T.: Cosmic ray contributions to dose rates for luminescence and ESR dating: large depths and longterm time variations, Radiat. Meas., 23, 497-500, 1994.

Qian, Y. and Jin, H. L.: Study on Oasis along the Silk Road, Xinjiang people's publishing house, Urumqi, China, 2010 (in Chinese).

Qiang, M. R., Chen, F. H., Zhang, J. W., Gao, S. Y., and Zhou, A. F.: Climatic changes documented by stable isotopes of sedimentary carbonate in Lake Sugan, northeastern Tibetan Plateau of China, since 2 ka BP, Chinese Sci. Bull., 50, 1930-1939, 2005.

Reimer, P. J., Bard, E., Bayliss, A., Beck. J. W., Blackwell, P. G., Ramsey, C. B., Buck, C. E., Cheng, H., Edwards, R. L., Friedrich, M., Grootes, P. M., Guilderson, T. P., Haflidason, H., Hajdas, I., Hatte, C., Heaton, T. J., Hoffmann, D. L., Hogg, A. G., Hughen, K. A., Kaiser, K. F., Kromer, B., Manning, S. W., Niu, M., Reimer, R. W., Richards, D. A., Scott, E. M., Southon, J. R., Staff, R. A., Turney, C. S., and Plicht, J. V. D.: IntCal13 and Marine13 radiocarbon age calibration curves $0-50,000$ years cal BP, Radiocarbon, 55, 1869-1887, 2013.

Research Institute of History and Language of the Central Academy in Taiwan: Ming Yingzong Shilu, Taibei, Taiwan, 1962.

Sakai, A., Inoue, M., Fujita, K., Narama, C., Kubota, J., Nakawo, M., and Yao, T.: Variations in discharge from the Qilian mountains, northwest China, and its effect on the agricultural communities of the Heihe basin, over the last two millennia, Water Ecol., 4, 177-196, 2012. 
Schmid, B. V., Büntgen, U., Easterday, W. R., Ginzler, C., Walløe, L., Bramanti, B., and Stenseth, N. C.: Climate-driven introduction of the Black Death and successive plague reintroductions into Europe, P. Natl. Acad. Sci. USA, 112, 3020-3025, 2015.

Shui, S.: A discussion on the thirst-resisting ability of camel, J. Inner Mongolian College of Agriculture and Animal Husbandry, 11, 55-59, 1990 (in Chinese).

Stamp, L. D.: A history of land use in arid regions, Literary Licensing, LLC., Whitefish, USA, 1961.

Tan, L. C., Dong, G. H., An, Z. S., Edwards, R. L., Li, H. M., Li, D., Spengler, R., Cai, Y. J., Cheng, H., Lan, J. H., Orozbaev, R., Liu, R. L., Chen, J. H., Xu, H., and Chen, F. H.: Megadrought and cultural exchange along the proto-Silk Road, Sci. Bull., 66, 603-611, https://doi.org/10.1016/j.scib.2020.10.011, 2021.

Thompson, L. O., Yao, T., Davis, M. E., Henderson, K. A., MosleyThompson, E., Lin, P. N., Beer, J., Synal, H. A., Cole-Dai, J., and Bolzan, J. F.: Tropical climate instability: The last glacial cycle from a Qinghai-Tibetan ice core, Science, 276, 1821-1825, 1997.

Wang, H., Chen, J., Zhang, S., Zhang, D. D., Wang, Z., Xu, Q., Chen, S., Wang, S., Kang, S., and Chen, F.: A chironomid-based record of temperature variability during the past 4000 years in northern China and its possible societal implications, Clim. Past, 14, 383-396, https://doi.org/10.5194/cp-14-383-2018, 2018.

Wang, S. C.: The chronology of humanistic and environmental change during historical period in Hexi Corridor and neighbouring areas, China, in: Environment change and the rise and fall of human civilization in arid areas of northwest China, edited by: Yin, Z. S., Geological Publishing House, Beijing, China, 1992 (in Chinese).

Wang, Y., Li, L. J., and Zhang, W.G.: Exchange history of Eurasia, Lanzhou University Press, Lanzhou, China, 1-17, 2000 (in Chinese).

Weiss, H.: The genesis and collapse of 3rd millennium north Mesopotamian civilization, Science, 262, 1358-1358, 1993.

White, S. and Pei, Q.: Attribution of historical societal impacts and adaptations to climate and extreme events: integrating quantitative and qualitative perspectives, Climate reconstruction and impacts from the archives of societies, 2, 44-45, 2020.

Wilson, R., Anchukaitis, K., Briffa, K. R., Büntgen, U., Cook, E., D’Arrigo, R., Davi, N., Esper, J., Frank, D., Gunnarson, B., Hegerl, G., Helama, S., Klesse, S., Krusic, P. J., Linderholm, H. W., Myglan, V., Osborn, T. J., Rydval, M., Schneider, L., Schurer, A., Wiles, G., Zhang, P., and Zorita, E.: Last millennium northern hemisphere summer temperatures from tree rings: Part I: The long term context, Quat. Sci. Rev., 134, 1-18, 2016.
Xie, Y., Ward, R., Fang, C., and Qiao, B.: The urban system in West China: A case study along the midsection of the ancient Silk Road - He-Xi Corridor, Cities, 24, 60-73, 2007.

Yang, B., Qin, C., Bräuning, A., Burchardt, I., and Liu, J. J.: Rainfall history for the Hexi Corridor in the arid northwest China during the past 620 years derived from tree rings, Int. J. Climatol., 31, 1166-1176, 2011

Yang, B., Qin, C., Shi, F., and Sonechkin, D. M.: Tree ring-based annual streamflow reconstruction for the Heihe River in arid northwestern China from AD 575 and its implications for water resource management, Holocene, 22, 773-784, 2012.

Yang, B., Qin, C., Wang, J., He, M., Melvin, T. M., Osborn, T. J., and Briffa, K. R.: A 3,500-year tree-ring record of annual precipitation on the northeastern Tibetan Plateau, P. Natl. Acad. Sci. USA, 111, 2903-2908, 2014.

Yang, Y. S., Zhang, S. J., Oldknow, C., Qiu, M. H., Chen, T. T., Li, H. M., Cui, Y. F., Ren, L. L., Chen, G. K., Wang, H., and Dong, G. H.: Refined chronology of prehistoric cultures and its implication for re-evaluating human-environment relations in the Hexi Corridor, northwest China, Science China Earth Sciences, 62, 1578-1590, https://doi.org/10.1007/s11430-018-9375-4, 2019.

Yu, T.: A Complete History of the Western Regions, Zhongzhou Ancient Books Publishing House Co., Ltd., Zhengzhou, China, 2003 (in Chinese).

Yuan, G. Y. and Zhao, Z. Y.: Relationship between the rise and decline of ancient Loulan town and environmental changes, Chinese Geogr. Sci., 9, 78-82, 1999.

Zhai, S. D.: The changes of the beacon flint and the land Silk Road in Dunhuang, Gansu Social Sci., 5, 135-140, 2017 (in Chinese).

Zhang, J., Huang, X., Wang, Z., Yan, T., and Zhang, E.: A lateHolocene pollen record from the western Qilian Mountains and its implications for climate change and human activity along the Silk Road, Northwestern China. Holocene, 28, 1141-1150, 2018.

Zhang, Q. and Hu, Y. Q.: The geographical features and climatic effects of oasis, Adv. Earth Sci., 17, 477-486, 2002.

Zhang, T. Y.: History of Ming dynasty, China Publishing House, Beijing, China, 1974 (in Chinese).

Zhou, X. Y., Li, X. Q., Dodson, J., and Zhao, K. L.: Rapid agricultural transformation in the prehistoric Hexi corridor, China. Quatern. Int., 426, 33-41, 2016. 